\title{
Nursing Now AEESME
}

\section{Dr. Francisco Megías-Lizancos}

Presidente de la Asociación Española de Enfermería de Salud Mental (AEESME).

Contacto: aeesme.aeesme@gmail.com

Fecha de recepción: 26 de febrero de 2020 / Fecha de aceptación: 16 de marzo de 2020

La campaña mundial Nursing Now, de tres años de duración (2018-2020), se basa en las aportaciones del informe Triple Impacto. Este informe concluye que el empoderamiento de las enfermeras llevaría a conseguir más igualdad de género, así como conseguir economías más fuertes, lo que redundaría de manera contundente en mejorar la salud y bienestar de la población a escala mundial.

Nursing Now surge con el objetivo de que las enfermeras sean la clave de la solución a los retos de salud en la actualidad, siempre que se implementen, se valoren y se les posibilite el estar en los lugares oportunos de toma de decisiones en salud. Por ello, se plantean cinco grandes objetivos:

1. Invertir más en la mejora de la educación, el desarrollo profesional, los estándares de calidad, la regulación y las condiciones de empleo para las enfermeras.

2. Aumentar, mejorar y difundir la efectividad del trabajo enfermero, dando a conocer los avances más innovadores.

3. Conseguir mayor influencia de las enfermeras y matronas en las políticas a nivel de los Estados y a nivel mundial, garantizando su involucración en la toma de decisiones.

4. Tener más enfermeras en posiciones de liderazgo, lo que asegurará más oportunidades de desarrollo en todos los niveles.

5. Aportar más evidencia a los responsables de las decisiones políticas para que identifiquen dónde las enfermeras pueden tener mayor impacto, reconociendo el alcance de su potencial y abordando los obstáculos que lo impiden.

No hace mucho, Nursing Now y el Consejo Internacional de Enfermería (CIE) estaban viviendo el cumplimiento de uno de sus objetivos estratégicos. Durante la $72^{\mathrm{a}}$ Asamblea Mundial de la Salud, celebrada en mayo de 2019 en Ginebra, se acordó por unanimidad declarar 2020 como el Año Internacional de la Enfermeras y las Matronas.

Fue el director general de la Organización Mundial de la Salud (OMS), Tedros Adhanom Ghebreyesus, quien defendió personalmente la proclamación de este año mundial enfermero destacando la labor que hacen las enfermeras a través de su trabajo en el ámbito asistencial, en la investigación, en la gestión, la docencia y muy especialmente con actividades de información sanitaria, prevención de la enfermedad y promoción de la salud y educación para la salud.

El CIE y la campaña Nursing Now consideraban que esta declaración para 2020 permitiría revelar los beneficios de tener personal de enfermería con la formación y los recursos adecuados en todos los países del mundo.

De esta manera, por primera vez, todos los países se unieron para rendir homenaje a la fundamental aportación a la salud de las personas que llevan a cabo diariamente los profesionales de enfermería, quienes querían que 2020 fuera un año colmado de acciones para dar visibilidad y acercar a la población en general la importantísima labor que realizan.

Dentro de este contexto, el Consejo General de Enfermería (CGE) de España, como representante de nuestro país en el CIE, impulsó la constitución del grupo Nursing Now España, integrado por 23 personas: el presidente del CGE y representantes del Ministerio de Sanidad, las tres organizaciones nacionales de pacientes, la Conferencia Nacional 
de Decanos de Enfermería, la Asociación Estatal de Estudiantes de Enfermería, los medios de comunicación y 15 asociaciones y sociedades científicas de enfermería, entre las que se encuentra la Asociación Española de Enfermería de Salud Mental (AEESME), representada por su presidente.

Este grupo se formó en mayo del pasado año, y desde entonces eran ya muchas las acciones llevadas a cabo en aras de avanzar en la salud y potenciar el papel de las enfermeras y la excelencia en la formación de los nuevos profesionales.

Sin embargo, y dado el contexto de la crisis del COVID-19, todo este plan de acción se ha visto truncado ante la necesidad de centrar todos los esfuerzos en la lucha contra la pandemia, paralizándose así todas las celebraciones de este año mundial. No obstante, estos nuevos retos a los que se están enfrentando las enfermeras en la actualidad están abriendo nuevas oportunidades, pues suponen una contribución al empoderamiento de las mismas, dando gran visibilidad a una profesión que se está esforzando día tras día, dejándose la piel y el alma para sacar al mundo de la mayor crisis sanitaria a la que nos hemos enfrentado en los últimos tiempos. Es de justicia que las enfermeras logren la visibilidad que se merecen.

Y es por este motivo que la OMS, a petición del CIE, ha decidido prorrogar este Año Internacional de la Enfermera y la Matrona hasta julio de 2021. Esta decisión supone así una oportunidad para continuar concienciando a la sociedad de la importante labor de la enfermera y de la necesidad de aprovechar al máximo el potencial enfermero, dando a esta profesión su merecido reconocimiento.

En todo este contexto, la AEESME, entre otras actividades, ya ha firmado acuerdos de colaboración con los Colegios Oficiales de Enfermería de Granada, Cádiz y Navarra. Además, en su próximo XXXVII Congreso Nacional y $3^{\text {a }}$ Conferencia Internacional de Enfermería de Salud Mental, que este año se celebrará de manera virtual, tiene reservado a este cometido un espacio privilegiado, al que asistirán presidentes de las diferentes Sociedades Científicas Estatales y en el que la Dra. Adelaida Zabalegui Yarnoz, representante de la Enfermería Europea en la Junta Directiva de Nursing Now, expondrá los retos y oportunidades del movimiento.

Además, y en consonancia con los objetivos perseguidos por Nursing Now, la AEESME ha presentado su "Decálogo \#NursingNowAEESME para alentar el desarrollo de todo el potencial de la enfermería de salud mental española a través del arte y ciencia de los cuidados", que pueden ver en páginas posteriores.

Asimismo, y dentro de esta línea de acción, la AEESME ha decidido dar paso a esta publicación de su Revista Española de Enfermería de Salud Mental (REESME), que versa exclusivamente sobre este movimiento, y en la que participan profesionales enfermeros de reconocido prestigio.

Aprovechamos desde aquí para dirigirnos a nuestros lectores y animarles a que participen activamente en este movimiento. La AEESME siempre estará abierta para colaborar en los distintos proyectos que los profesionales de enfermería propongan, así como a sugerencias sobre acciones que se quieran poner en marcha.

No queremos terminar sin hacer llegar a todas las enfermeras y enfermeros nuestro infinito agradecimiento por la gran labor que están desarrollando cada día. Reconocemos y queremos resaltar su valentía y sacrificio; su bondad y empatía; su capacidad para adaptarse a la adversidad y superar obstáculos; sus extraordinarios esfuerzos por alcanzar el bien común; su disposición y saber hacer; en definitiva, queremos agradecer y resaltar su PRESENCIA. Y apostamos por que este período 2020-2021 que se ha designado como Año Internacional de la Enfermera y la Matrona sirva para crear la confianza necesaria con la población y conjuntamente llegar a las más altas cotas de calidad de vida para todos. 